\title{
Grief therapy for those left behind
}

$\mathrm{P}$ alliative care programs are primarily designed to provide care and comfort to dying patients, but most also attempt to help patients' bereaved families cope with their loss.

At least in theory.

"Care of the family is part of the rhetoric of palliative care - supporting children and spouses, as well as the dying patient. While that is an admirable goal, putting that into a model that works well is challenging to do," says Dr. David Kissane, chair of the department of psychiatry and behavioural sciences at Memorial Sloan-Kettering Cancer Center in New York City, New York. "In practice, most of the focus is on the patient. The broad principle of supporting the family is there but doesn't always get translated into practice."

It is only natural, says Kissane, that palliative care programs focus more on active patients than on the families of deceased patients. Hospices can use only so much of their limited resources on services for bereaved families, so those services are usually offered for limited periods.

In a randomized, controlled trial of family-focused grief therapy in palliative care and bereavement, Kissane divided bereaved families into three classes: well-functioning, intermediate and dysfunctional (Am J Psychiatry 2006; 163:1208-18). Well-functioning families, which make up the majority, are equipped to handle the grieving process. Dysfunctional families, which make up $15 \%-20 \%$ of families of patients receiving palliative care, have high levels of conflict and poor communication. In between are the intermediate families, which are moderately cohesive but tend to break down under the stress of death and bereavement.

Members of families that fall into the dysfunctional and intermediate classes are more prone to experience complicated grief, also known as pathological grief, which can lead to clinical depression, substance abuse, suicidal thoughts

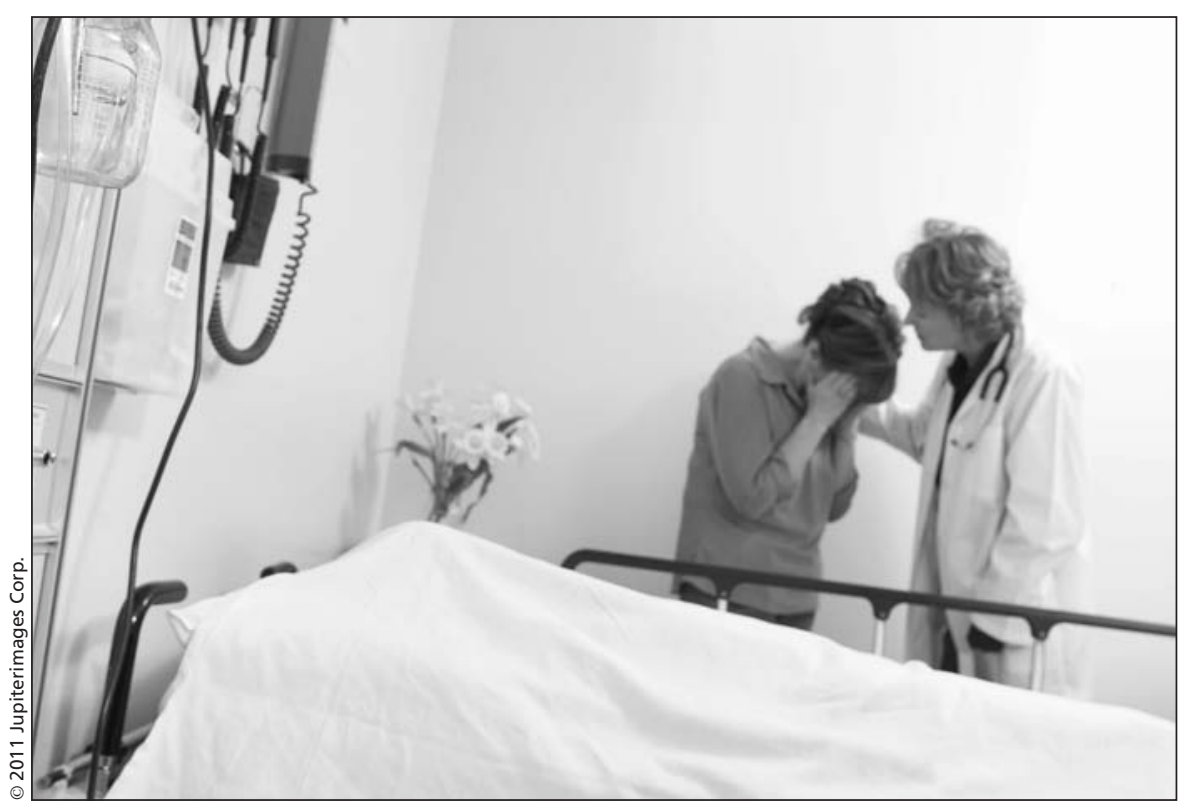

A projected $10 \%-15 \%$ of bereaved people struggle to adjust to the loss of a loved one.

and other forms of impairment. "That means you have to screen the families and determine which are in need of therapy. The answer lies in the quality of the relationships in the family unit," says Kissane. "Families that are wellfunctioning and supportive and have effective communicators, when you follow them through palliative care the bereavement process, they do well. They adapt. You have to search really hard to find any instances of mild depression or complicated grief. That's not where you should target your resources."

According to the trial, dysfunctional families categorized as "hostile" tend to reject grief therapy. But dysfunctional families categorized as "sullen" were more open to receiving help and, indeed, showed the most benefit from familyfocused grief therapy. "Our data indicate that family focused grief therapy reduces stress and protects partially against pathological grief," the study concludes. "Families with a sullen or intermediate class of functioning are particularly suited for preventive intervention with family focused therapy, while members of hostile families may be better helped individually."
On an individual basis, $10 \%-15 \%$ of bereaved people struggle to adjust to the loss of a loved one, according to a recent analysis of 61 studies (Curr Dir Psychol Sci 2009; 18:352-6). "A significant minority deal with debilitating grief that strips their lives of any sense of purpose and joy, and leaves them unable to fully engage in opportunities and relationships," says Robert Neimeyer, professor in the department of psychology at the University of Memphis in Tennessee. "But there are two forms of good news about grief therapy. The first is the reality of resilience for many people. The majority of people don't need professional therapy. The second is that grief therapy is effective for those who need it."

Among those who need grief therapy more than most are parents and siblings of children who die in palliative care. More so than most palliative care programs, pediatric hospices provide longterm bereavement services to families of deceased patients. For example, Canuck Place, a pediatric hospice in Vancouver, British Columbia, sends cards to families of deceased children on patients' birthdays and on the anniversaries of their deaths for three years. It also runs 
simultaneous bereavement therapy programs for siblings and parents, who typically attend for up to a year. There is even a bereavement alumni group for parents of children who have been dead for several years.

"In order to support a child, you need to support a whole family," says Kerry Keats, bereavement services coordinator for Canuck Place. "Part of our role it to integrate our services so they are fluid, so there is a continuity of care. Families receive care while a child is dying and also afterwards. We look at the whole family, parents and siblings."

Some adult hospices also offer grief therapy services to families of deceased patients, though usually for shorter periods. For instance, the Hospice at May Court, a nine-bed palliative facility in Ottawa, Ontario, sends a sympathy card to families of deceased patients that lets them know that bereavement counselling with a social worker is available to them at no cost. A few weeks later, families are contacted by staff to see how they are managing. Some people come in to receive therapy; some don't.

"It varies because grief is so individual," says Francine Beaupre, a social worker and family support program coordinator at the hospice.

Adult hospices that don't offer grief therapy services often link bereaved family members to existing services in the community. These could be free peer-support groups or volunteer services, or psychologists whose services may be covered under private insurance plans. If the grief is pathological in nature and affecting overall health, links can be made to family doctors and psychiatrists, whose services are covered under medicare.

"Good palliative care includes care for both anticipatory loss and afterdeath loss," says Belinda Marchese, director of clinical services for Hospice Toronto in Ontario. "It's part of our philosophy of care to make those links to support services." - Roger Collier, CMAJ

CMAJ 2011. DOI:10.1503/cmaj.109-3793

\section{Part I: Preparing for the inevitable}

Editor's note: Ninth of a series on end-of-life care

(www.cmaj.ca/cgi/doi/10.1503/cmaj.109-3704)

Part II: Advance directives: Obstacles in preparing for the worst (www.cmaj.ca/cgi/doi/10.1503/cmaj.109-3743)

Part III: End-of-life planning framework calls for fewer checklists, more conversation (www.cmaj.ca/cgi/doi/10.1503/cmaj.109-3746)

Part IV: Tools help patients tackle tough choices for end-of-life care (www.cmaj.ca/cgi/doi/10.1503/cmaj.109-3750)

Part V: National home care standards urged (www.cmaj.ca/cgi/doi/10.1503/cmaj.109-3731)

Part VI: Access to palliative care varies widely across Canada (www.cmaj.ca/cgi/doi/10.1503/cmaj.109-3763)

Part VII: Framework urges physicians to proceed with caution on palliative sedation (www.cmaj.ca/cgi/doi/10.1503/cmaj.109-3766)

Part VIII: Pocket-sized help for people with dementia (www.cmaj.ca/cgi/doi/10.1503/cmaj.109-3705) 